\title{
O SUJEITO EM FOCO: DO PARADIGMA FORMAL AO FUNCIONAL*
}

\author{
Jhuliane Evelyn da Silva ${ }^{* *}$ \\ Marco Antônio Margarido Costa ${ }^{* *}$
}

\begin{abstract}
Resumo: Ao longo da história da Linguística, deparamo-nos com diversos olhares sobre a língua(gem), seu objeto de estudo. Um dos elementos que acompanha essa trajetória é a noção de sujeito, que 'desconsiderado' inicialmente na concepção de ciência, logo é tomado como elemento chave para o seu desenvolvimento. Portanto, a partir de uma revisão bibliográfica, tencionamos expor a concepção de sujeito, situando-o dentro dos paradigmas formalista e funcionalista a partir das correntes teóricas: Estruturalismo, Gerativismo, Sociolinguística, Linguística Textual, Análise de Discurso e Letramento Crítico, de modo a revelá-lo como o consideramos atualmente, situado no paradigma da heterogeneidade. Depreendemos dessa trajetória que as correntes teóricas e seus conceitos, como frutos de escolhas, estão em constante mudança em resposta ao contexto ora vivenciado.
\end{abstract}

Palavras-chave: Sujeito. Formalismo. Funcionalismo.

Abstract: Throughout the history of linguistics, we are faced with different views on language. One element that accompanies this course is the notion of subject, 'disregarded' initially, but soon taken as a key element to its development. Therefore, from a literature review, we aim at exposing the concept of subject, situating it within the formalist and the functionalist paradigms from the following theoretical perspectives: Structuralism, Generativism, Sociolinguistics, Textual Linguistics, Discourse Analysis and Critical Literacy, in order to reveal it as it is currently considered, located on the paradigm of heterogeneity. As a result, we inferred that theoretical perspectives and concepts are constantly changing in response to the current context experienced.

Keywords: Subject. Formalism. Functionalism.

\section{Considerações iniciais}

Ao longo dos estudos linguísticos contemporâneos, muito se tem discutido sobre a noção de sujeito, que, ora é "desconsiderado", ora é reclamado como elemento essencial para se compreender a língua (objeto de estudo da ciência Linguística). Isso se deve ao fato de que, conforme Possenti (2004, p. 355),

o conhecimento não se produz por acumulação, mas por saltos e mudanças de rumo em relação às etapas anteriores. As novas teorias não são vistas como desenvolvimento e sofisticação das anteriores, mas como efeito, em boa medida, de seu abandono, seja por estarem "esgotadas", seja porque novas problemáticas, novas vontades de verdade tomam seu lugar, tanto teórica quanto politicamente.

Dito de outro modo, o desenvolvimento da ciência não se dá de forma linear. Se assim fosse, teríamos a linguística saussureana amplamente estudada e aprofundada e não tão questionada como, na verdade, a compreendemos atualmente. $\mathrm{O}$ que houve foi uma mudança

\footnotetext{
* Artigo apresentado à disciplina Estudos Linguísticos Contemporâneos, ofertada pelo Programa de PósGraduação em Linguagem e Ensino, em 2013.1.

** Graduada em Letras -Língua Inglesa pela UERN. Mestranda pelo Programa de Pós-Graduação em Linguagem e Ensino (POSLE) da UFCG - Universidade Federal de Campina Grande, Campina Grande/PB. Endereço eletrônico: anecomjesus@gmail.com .

*** Professor Adjunto da UFCG - Universidade Federal de Campina Grande. Doutor em Letras pela Universidade de São Paulo. Endereço eletrônico: marcanco@terra.com.br .
} 
de rumo, retomando as palavras do autor, um novo modo de apreender/perceber o objeto de estudo - a linguagem.

Saussure, considerado o pai da Linguística moderna, definiu um corte, necessário àquela época, com o objetivo de elevar a Linguística a seu patamar de ciência. Para tanto, preciso foi considerar os moldes determinados pelo Positivismo a fim de validar tal propósito. Este corte, por sua vez, o levou a estudar o observável, o sistematizável, o homogêneo, o social de seu objeto observacional, elegendo, portanto, a língua (langue) e relegando, consequentemente, a fala (parole) por ser individual, heterogênea e não passível de sistematização.

A partir desse corte, Saussure inaugurou a Linguística nos moldes científicos. No entanto, ao mesmo tempo em que escolhe lidar com esse objeto de forma abstrata e descontextualizada, outros teóricos $\mathrm{o}$ percebem de forma diferente $\mathrm{e}$ defendem a impossibilidade de se enxergar a língua fora de seu contexto de uso, sem considerar sua função, o discurso, a história, a memória, o sujeito. É assim que outras correntes teóricas aparecem e, criticando as faltas encontradas nas teorias já aceitas, propõem um novo olhar e com ele, novas características e novos modos de compreender a linguagem e as ações que ela permeia.

Destarte, este trabalho busca elucidar a constituição do conceito de sujeito que, embora compreendida como não linear, sofre influências diversas dos estudos que vão sendo desenvolvidos bem como do contexto no qual se inserem. Ademais, procura explicitar como cada corrente linguística, aqui exposta brevemente, leva o conceito de sujeito em consideração na tessitura de sua proposta teórica. Para tal, empreendeu-se uma pesquisa de caráter bibliográfico (MOREIRA; CALEFFE, 2008), que está dividida em dois momentos. No primeiro, apresentaremos como o paradigma da homogeneidade (ou formalista) concebeu o sujeito em seus estudos. No segundo, apresentaremos essa concepção, considerando as proposições do paradigma da heterogeneidade (ou funcionalista), aqui representado pela Sociolinguística, pela Linguística Textual, pela Análise de Discurso de vertente francesa e pelos estudos recentes sobre letramentos, especificamente pelo Letramento Crítico.

\section{A noção de sujeito no paradigma formalista}

\subsection{Afinal, há sujeito na teoria saussureana?}

Ao levarmos em consideração a assertiva de Saussure (2007) que é o ponto de vista que cria o objeto, podemos dizer que ele tomou por objeto a língua, e mais especificamente, tomou-a por sistema, excluindo a fala e consequentemente o sujeito. Esta escolha guiou o desenvolvimento de seus estudos.

Elegendo a língua (langue) como objeto de estudo e excluindo a fala (parole) de seus estudos linguísticos - com a finalidade de conferir coerência metodológica e cientificidade a esse objeto - Saussure relega a relevância da noção de fala e de sujeito em sua teoria.

Não obstante, o mestre genebrino elucida o conceito de língua como um fato social e é nesse momento que sua teoria se volta aos falantes. Tomar a língua como social implica dizer que esta é compartilhada por todos os membros de uma comunidade. Nas palavras do autor, a língua seria "um produto social da faculdade de linguagem e um conjunto de convenções necessárias, adotadas pelo corpo social para permitir o exercício dessa faculdade nos indivíduos" (SAUSSURE, 2007 [1916], p.17). Sendo "a parte social da linguagem", Saussure defende que ela "não existe senão em virtude duma espécie de contrato estabelecido entre os membros da comunidade" (SAUSSURE, 2007 [1916], p. 22). 
Nesse sentido, a língua preexiste ao sujeito ao mesmo tempo em que é social, porque compartilhada. Vê-se de forma clara a importância atribuída ao sujeito, não influenciando sobre a mudança da língua, mas para sua constituição/existência. Diferentemente do sujeito cartesiano centrado, livre e autônomo, como fora na época postulado, o sujeito aqui é concebido como do inconsciente, descentrado (MARQUES, 2009). Isso pode ser percebido quando Saussure insiste que a língua escapa à vontade do sujeito:

Não há nenhum momento em que o sujeito submeta a uma revisão o tesouro mental da língua que ele tem em si, e crie, de espírito descansado, formas novas (por ex. calmamente [ ]) que ele se proponha (prometa) a "colocar" em seu próximo discurso. Toda inovação chega de improviso, ao falar, e penetra, daí, no tesouro íntimo do ouvinte ou no orador, mas se produz, portanto, a propósito de uma linguagem discursiva. (SAUSSURE, 2004, p. 87)

É na perspectiva de conceber o sujeito a partir do estudo do sistema, mesmo que não contemplado por Saussure, que emanam outras visões sobre o lugar/a existência desse 'falante' na teoria estrutural saussureana.

Apoiando-se em afirmações como "A língua é social ou então não existe. A língua para se impor ao espírito do indivíduo, deve antes ter a sanção da coletividade" (SAUSSURE, 2004, p. 258), autores como Basílio (2009) reclamam a presença do sujeito na teoria saussureana. Esta estudiosa ressalta que "O sujeito percebe as diferenças, ou seja, os valores criados pelo fato social e os coloca em uma relação específica dentro de um sintagma, gerando o valor a partir do fato sintagmático" (BASÍLIO, 2009, p. 5). Assim, afirma da existência do sujeito na estrutura da língua, especificamente, na teoria do valor linguístico, onde o sentido é gerado, tomando por base o que diz Saussure no Curso de Linguística Geral (CLG). Essa assertiva corrobora o que foi anteriormente afirmado, uma vez que essa noção de sujeito é apresentada pelo mestre genebrino por meio da língua como um fenômeno social.

Outra visão que emerge e concorda em sentido com o discutido por Basílio (op. cit.) é a de Silva (2011). Para ressaltar a presença do sujeito, tomado como falante na teoria estrutural, Silva (2011, p. 40) recorre à própria explicação da teoria no que diz respeito aos seus eixos constituintes: "O eixo sintagmático (mecanismo de combinação) é a realização da língua, representando a fala; o eixo paradigmático (mecanismo de seleção) representa o plano da língua, sistema disponível na memória do falante." Nesse sentido, as relações associativas (paradigmáticas) diferentemente das relações sintagmáticas dependem do falante, uma vez que "as palavras que oferecem algo em comum se associam na memória e assim se formam grupos dentro dos quais imperam relações muito diversas. [...] sua sede está no cérebro; elas fazem parte deste tesouro interior que constitui a língua de cada indivíduo" (SILVA, 2011, p. 40).

Por fim, Nóbrega (2008) corrobora os autores supracitados, quando compreende que "a organização sintagmática e a escolha na cadeia associativa são obras de um sujeito falante e devem a ele ser atribuídas" (NÓBREGA, 2008, p. 9, grifos no original).

Concordamos com os autores supracitados, quando afirmam que Saussure não exclui o sujeito em seus estudos, apenas não o contempla de forma central, detendo-se nele. Aliás, não era objetivo do mestre genebrino, devemos deixar claro, tratar da noção de sujeito. O que queria exclusivamente era trazer a noção de língua como um sistema. Por isso que, a partir de seu corte entre língua e fala, o autor elege a língua e rejeita a fala, relegando, portanto, o papel da heterogeneidade e da subjetividade bem como de fatores externos em sua teoria. Para confirmar essa tese, Saussure retira do sujeito o poder de autoria da língua, ao postular que o 
signo linguístico é arbitrário, coletivamente convencionado, e este, sendo social, preexiste e é exterior ao sujeito. Ademais, ainda o caracteriza como imutável, retirando a autoridade do sujeito para modificá-lo, ficando a cargo da sociedade, de fatores externos, a mudança da língua.

\section{2 De sujeito a indivíduo}

Dando continuidade aos estudos científicos sobre a língua e em contraposição à crença de que esta era um condicionamento social como, na época, a Linguística Estrutural Behaviorista fazia acreditar, Chomsky propõe, em meados do século XX com seu livro Syntatic Structures, o seu modelo gerativo de gramática. Neste, ele busca, além de descrever, explicar o que e como a linguagem humana funciona. Para tanto, concebe a língua como "um conjunto (finito ou infinito) de sentenças, cada uma finita em comprimento e construída a partir de um conjunto finito de elementos" (CHOMSKY, 1957, p. 13).

Chomsky baseia seus postulados teóricos na premissa de que o ser humano, diverso a todos os outros seres, possui uma competência inata para a língua(gem). Desse modo, sua gramática descreve o aspecto criativo que permite aos seres humanos gerar infinitas frases e compreender expressões nunca antes ouvidas. Contudo, seu foco não recai na língua em si, mas, do mesmo modo que Saussure determina como objeto de estudo a língua e rejeita a fala, Chomsky considera, inicialmente, a competência em detrimento do desempenho.

A competência se caracteriza como "o conhecimento internalizado que os falantes possuem de uma língua para permitir o uso do conjunto de regras que se encontram presentes em sua mente no uso da linguagem" (SILVA, 2011, p. 44). O desempenho, por sua vez, seria o uso dessa competência levando em consideração aspectos extralinguísticos como a sociedade, os interlocutores e o ambiente.

Destacamos o advérbio 'inicialmente' porque o gerativismo vem sofrendo modificações ao longo desses anos, deslocando seu objeto da competência para os universais linguísticos, e, posteriormente, para a noção de língua $-\mathrm{I}^{1}$, para o estado inicial da faculdade de linguagem, para a gramática do linguista e para a GU (CHOMSKY, 1994).

Por fim, ao escolher focalizar a competência (ou L-I), de caráter universal e que está contida no cérebro dos falantes como uma propriedade inata, Chomsky caracteriza os falantes (sujeitos de sua teoria) como indivíduos, uma vez que são tomados por sua natureza biológica e não social. Cumpre dizer ainda que este indivíduo não é real, mas idealizado, pertencente a uma comunidade linguística hipotética. Nas palavras do autor,

um falante-ouvinte ideal, situado numa comunidade linguística completamente homogênea, que conhece a sua língua perfeitamente, e que, ao aplicar o seu conhecimento da língua numa performance efetiva, não é afetado por condições gramaticalmente irrelevantes, tais como limitações de memória, distrações, desvios de atenção e de interesse, e erros (causais ou característicos) (CHOMSKY, 1975, p. 84).

Essas abstrações, para esse teórico, se fazem necessárias para a construção de uma teoria científica de língua. Nessa perspectiva, o gerativismo teve grande contribuição para os estudos linguísticos e para os estudos cognitivistas, ao promover o deslocamento das línguas

\footnotetext{
1 "Realização específica das opções permitidas pela GU, fixada pela experiência” (CHOMSKY, 1994, p. 62). Entenda-se GU por Gramática Universal, conceito defendido por Chomsky para caracterizar uma “formalização analítica da faculdade humana de linguagem” (LUCCHESI, 2004, p. 197).
} 
como produtos de uma atividade biológica evolutiva natural da espécie, em especial, para protocolar situações de fala em sujeitos com problemas de linguagem, como dislexia, dislalia, entre outros.

\section{A noção de sujeito no paradigma funcionalista: de sujeito a falante}

Com vistas a trazer a visão funcionalista aos estudos linguísticos, Martelotta e Áreas (2003 apud MARQUES, 2009, p. 4) afirmam que, após a publicação do CLG, três foram as noções que se tornaram centrais para a Linguística, quais sejam: sistema, estrutura e função. As primeiras são estudadas por Saussure, quando postula que o sistema prioriza o todo em relação às partes. O sistema, posteriormente, receberá o nome de estrutura, isto é, "um sistema constituído por uma rede de elementos, em que cada elemento tem um valor funcional específico" (BARBOSA, 2013, p. 21). A última, função, tem início com o Círculo Linguístico de Praga, que a entendia como elemento indispensável ao estudo da língua, com grande fôlego para a fonologia.

Utilizada por diversos estudiosos com significações distintas, o termo função encontra sua inauguração no Círculo Linguístico de Praga, atuante entre 1928 a 1939, com o sentido do papel que a língua desempenha na sociedade, isto é, das relações que a língua estabelece com o meio (LUCCHESI, 2004). Vachek (1978, p. 32 apud LUCCHESI, 2004, p. 87) declara que

Esse tipo de análise considera a língua como um instrumento que desempenha um certo número de funções ou tarefas essenciais na comunidade que a utiliza. A mais notável (e a mais óbvia) dessas tarefas é indubitavelmente a função comunicativa, que supre a necessidade de comunicação mútua entre os indivíduos.

Outra teoria de grande importância nesse paradigma é a Linguística SistêmicoFuncional (doravante LSF) postulada por Halliday (2004) nos anos 1970. Essa é uma teoria linguística centrada nas funções da linguagem, que se ocupa tanto do significado quanto da estrutura das mensagens, pois estuda a língua como um todo, tomando o significado como determinador da forma, diferentemente das abordagens formais que costumam estudá-la somente por meio da estrutura.

A LSF não acredita que a forma exista sem/antes do conteúdo, ao passo que os dois se completam e servem de acordo com o que o falante deseja significar. A gramática sob essa abordagem é concebida "como um sistema de opções à disposição do falante/escritor, que faz diferentes escolhas linguísticas visando atingir diferentes significados, levando em consideração contextos sócio-culturais variados" (WILSON, 2008, p. 56). Ou seja, a gramática forneceria a seu usuário uma gama de significados potenciais com os quais aqueles se utilizariam a partir de sua escolha para atingir seus propósitos comunicativos num dado contexto de uso.

Em termos gerais, o paradigma funcional serve-se da compreensão de que a língua funciona de acordo com a necessidade dos falantes. Diferentemente do paradigma formalista que considera o estudo da língua pela língua, isto é, enfoca seus aspectos meramente formais, o funcionalista traz à tona conceitos outros que buscam lidar com a heterogeneidade presente na exterioridade. Tal heterogeneidade abarca, então, tudo o que faz referência ao contexto, à situação de produção, aos sujeitos nela envolvidos, à historicidade. Em outras palavras, o paradigma funcional não desconsidera os fatores extralinguísticos e o contexto que 
influenciam a fala, mas, ao contrário, articula esses elementos em favor de sua teoria linguística.

Consideremos, então, teorias outras, que diferentemente do paradigma formalista, consideram central o papel do sujeito. Apesar de muitas, as aqui apresentadas resumir-se-ão à Sociolinguística, à Linguística Textual, à Análise de Discurso e ao Letramento Crítico.

\subsection{Sociolinguística}

Descontente com a noção de língua como sistema estudado somente em sua dimensão sincrônica e que desconsidera a fala, Labov, na década de 1960, elabora uma teoria que busca preencher as lacunas deixadas pelas teorias já aceitas, focando principalmente a questão da mudança linguística, "concluindo que interação, variação e sociedade são fatores indissociados do fenômeno linguístico" (ARAÚJO; RAFAEL; AMORIM, 2013, p. 34).

Inicia, então, elegendo a comunidade de fala como seu objeto de investigação e institui a Sociolinguística variacionista, que almeja tratar da relação entre língua e sociedade. Para tanto, esta disciplina traz a influência dos fatores extralinguísticos sobre a estrutura da língua. Recai sobre o falante a responsabilidade de escolher/adaptar sua língua valendo-se de sua competência comunicativa, ao contexto de fala, também entendido como situação imediata.

No entanto, considerando a língua heterogênea, Labov atribui homogeneidade à comunidade de fala, pelo menos no que diz respeito às atitudes dos falantes no que concerne à língua, como se faz possível observar no excerto abaixo,

esperava-se que, ao nos concentrarmos sobre os julgamentos dos falantes nativos ao invés de sua fala real, muito desta variação poderia ser desviada. De certa forma, esta esperança justifica-se: membros de uma comunidade de fala compartilham um conjunto comum de padrões normativos, mesmo quando nós encontramos variação altamente estratificada na fala real. (LABOV, 1972, p. 192).

Em outras palavras, para essa corrente teórica, o sujeito, tomado como indivíduo, está subordinado à comunidade de fala. Figueroa (1994 apud SEVERO, 2008) critica, assim, a negação do papel do indivíduo e a acepção de categorias supra-individuais, como raça, classe e gênero, fatores esses que seriam utilizados somente para rotulação/classificação para fins metodológicos do tipo social a ser considerado em pesquisas. Consequentemente, o indivíduo não influenciaria ou pelo menos não seria a fonte da mudança no sistema. Reiterando o exposto, Pagotto (2004, p. 76 apud SEVERO, 2008, p. 10) afirma que "não se trata de um indivíduo senhor de si e do processo de variação"; ele "é apenas uma instância onde se materializam as forças operantes em tal comunidade linguística, aqui, novamente, entendidas não como vetores de uma fonte externa, mas como integrantes de um sistema".

\subsection{Linguística Textual}

A partir da noção de signo introduzida por Saussure e de sintagma reclamada por Chomsky ambos no paradigma estruturalista de linguagem, o enfoque da análise linguística se dá na tomada da frase a partir de seu escrutínio em elementos menores, sempre de forma descontextualizada. No entanto, após um amplo esforço teórico, surge, a partir dos estudos de Harald Weinrich, na década de 1960, uma linguística voltada para o estudo da língua a partir 
do texto/discurso, a qual busca ir além dos limites da frase, extrapolando essas fronteiras em direção ao sujeito e à situação de comunicação (BENTES, 2001).

Podemos, todavia, afirmar que essa linguística não se desenvolveu de forma homogênea em todas as correntes teóricas em diversas partes do mundo, e é em virtude desse fato que se faz possível demarcar três períodos distintos desde sua constituição. Em um primeiro momento, o enfoque se dava na análise transfrástica, isto é, na análise de elementos os quais não poderiam ser explicados através de teorias que se limitassem ao estudo da frase, como o fenômeno da co-referenciação. Assim, estudavam-se as relações existentes entre a frase e o período, partindo da frase para o texto de modo a construir uma unidade de sentido. Em um segundo momento, o estudo voltou-se para a construção de gramáticas textuais a partir da influência, em sua gênese, da gramática gerativa. Destarte, um sistema de regras comum aos usuários de determinada língua (competência textual) lhes capacitaria dizer se uma sequência seria um texto (bem escrito) ou não (BENTES, 2001). Por fim, em um terceiro momento, quando ocorre a chamada guinada pragmática nos estudos da linguagem, a Linguística Textual (LT) foca nos aspectos contextuais e de interação, trazendo à tona a língua como "um lugar de interação e de produção de sentidos" (HEINE, 2008, p. 47), bem como a presença do interlocutor, (intencionalidade do produtor, aceitabilidade do receptor), além de fatores de textualidade, coerência e coesão, situacionalidade, informatividade e intertextualidade.

Heine (2008) continua elucidando de forma mais incisiva a posição do sujeito, quando diz que "Para os seguidores da LT, a ciência da linguagem devia voltar-se para o estudo do texto, porque o falante se comunica através de textos, sua forma específica de manifestação da linguagem" (HEINE, 2008, p. 329), diferentemente do que propunha Saussure, ao delimitar a língua e seu estudo descontextualizado e em si mesma.

A língua (dialógica e interativa) é então pela LT compreendida "como uma forma específica de comunicação social da atividade humana, interconectada com outras atividades (não linguísticas) do ser humano" (KOCH, 2004, p. 14) O sujeito pragmático é, portanto, um sujeito de vontade própria que almeja conscientemente atingir seu interlocutor de alguma forma (cf. HEINE, 2008).

\subsection{Análise de Discurso: um sujeito desdobrado}

Abrindo o escopo dos estudos linguísticos, a Análise de Discurso (AD) de vertente francesa vem a ser resultado já de amplas discussões que não mais se preocupam especificamente com a língua em sua estrutura. Aqui, é o discurso que é tomado como objeto de estudo, e este é entendido como sendo exterior à língua, no qual o aspecto ideológico e o social se unem e se materializam por meio da linguagem. A AD, assim, é um ramo da Linguística que, ao contrário desta, não concebe a língua como um sistema abstrato, mas como "palavra em movimento, prática de linguagem" (ORLANDI, 2002, p. 15).

Apresenta-se, então, como uma disciplina que figura entre a Linguística e as Ciências Sociais e que toma a língua como ponto de partida (materialização do discurso) para chegar ao contexto social e histórico do discurso. Esta disciplina analisa as condições de produção do discurso, caracterizadas pela situação e posição de quem enuncia o discurso numa determinada estrutura social, haja vista não haver discurso sem sujeito nem sujeito sem ideologia ou inconsciente.

Seu objetivo é "compreender a língua fazendo sentido, enquanto trabalho simbólico, parte do trabalho social geral, constitutivo do homem e da sua história" (ORLANDI, 2002, 
p.15). Assim, a $A D$ concebe a linguagem no social, na história e a partir das condições de produção em que foi gerada, e tenta desmontar o jogo ideológico que está impresso na língua.

Enfim, consoante Fernandes (2005, p. 20) "o discurso implica uma exterioridade à língua, encontra-se no social e envolve questões [...] de aspectos sociais e ideológicos impregnados nas palavras quando elas são pronunciadas". Em outras palavras, a língua tem que estar inserida na história, no social para produzir sentido, sendo que este é atravessado e ainda produzido pelas ideologias de diversos sujeitos.

Os discursos ainda exprimem uma memória coletiva na qual os sujeitos estão inseridos. Assim, "a história do presente, promovida na mídia, é, portanto, uma representação social do passado, entrecruzada pela memória e pela história" (ZANUTTO; NAVARRO, 2010, p. 42). Nesse sentido, há um movimento de discursos que se entrecruzam no passado e no presente e que se imprimem no discurso atual trazendo vestígios da memória de outros discursos. Por esse movimento, ao trazer outras vozes atravessadas em si, a memória presentifica o que já foi dito e lhe dá uma nova roupagem. Daí há a produção de sentidos do enunciado, uma vez que esta não pode se dar fora das redes de memória que atualiza (SILVA, 2010).

Dito isto, continuamos afirmando que, assim como a LT, a AD passou por fases distintas que ampliaram seu raio de ação. Nas linhas seguintes, tentaremos mostrar somente como o conceito de sujeito foi sendo alterado. Na primeira fase, Pêcheux traz o sujeito como assujeitado pela maquinaria discursiva, uma vez que este estaria a serviço dos Aparelhos Ideológicos do Estado. Dito de outro modo, "a ideologia funciona pela constituição ('interpelação') das pessoas em sujeitos sociais e sua fixação em 'posições' de sujeito, enquanto ao mesmo tempo lhes dá a ilusão de serem agentes livres." (FAIRCLOUGH, 2001, p. 52). Importante faz-se destacar que, por muito tempo, perdurou a ideia de sujeito assujeitado por ser comandado por seu inconsciente, pela ideologia e pela estrutura social, porém, tal noção não mais se insere nesta corrente teórica.

Na segunda fase, há a introdução da noção foulcaultiana de Formação Discursiva (FD), "aquilo que em uma dada formação ideológica... determina 'o que pode e deve ser dito"” (PÊCHEUX, 1982, p. 111). Desse modo, vemos um sujeito não mais assujeitado, mas também não livre, pois se encontra em dispersão ao filiar-se a diversas FDs, que tem o papel de regular seu discurso. O sujeito aqui tem a ilusão de ser origem do seu dizer, não percebendo que as FDs o constituem.

$\mathrm{Na}$ terceira fase, por fim, a unidade de análise deixa de ser o discurso e passa a ser o interdiscurso, isto é, "o espaço de trocas entre vários discursos convenientemente escolhidos" (MAINGUENEAU apud BRANDÃO, 1997, p. 72). Como consequência, a AD apresenta um sujeito falante, locutor e enunciador, atravessado por vozes. Essa noção dialógica vem de Bakhtin, que postula a atuação do sujeito sempre como resposta à presença do outro.

Nessa perspectiva, vemos duas exterioridades constituindo o ser: o "outro" como interlocutor e o "Outro" como interdiscurso (BRANDÃO, 1990). Para a AD, o sujeito discursivo-ideológico deve ser visto como

um ser social, apreendido em um espaço coletivo; portanto, trata-se de um sujeito não fundamentado em uma individualidade, em um "eu" individualizado, e sim um sujeito que tem existência em um espaço social e ideológico, em um dado momento da história e não em outro. (FERNANDES, 2007, p. 33-34).

Ou seja, a exterioridade é vista como constituinte do sujeito. Este se constitui na sociedade por meio da linguagem e esta é exterior ao mesmo. Apesar de acreditar ser o centro de seu 
dizer, o sujeito é o "suporte e o efeito do funcionamento discursivo que lhe é exterior" (MARQUES, 2009, p. 14). O sujeito é, assim, efeito da linguagem.

\subsection{A noção de sujeito no paradigma pós-moderno dos estudos de Letramento: de sujeito a agente crítico}

Extrapolando o campo dos estudos linguísticos formalista e funcionalista, e indo para a área de Linguística Aplicada ${ }^{2}$, pensamos na relevância de se considerarem os efeitos desses estudos em outras áreas da linguagem. Assim, decidimos apresentar também o conceito de sujeito nos estudos de Letramento, especificamente Letramento Crítico. Tal inserção justificase ainda pelo fato de que essa concepção aparece como resultado de diversas revoluções na área e que recebeu forte influência dos estudos linguísticos acima apresentados. Aqui, o foco recai na língua(gem) sob forma de leitura e escrita tomados como práticas socioculturais situadas.

Os estudos de Letramento, em sua concepção, distinguem as noções de alfabetização (decodificação linguística) e letramento (uso linguístico situado) e estabelece dois modelos, o autônomo e o ideológico (STREET, 1984). Resumidamente, o primeiro considera o letramento como possuindo papel central no desenvolvimento da competência intelectual dos indivíduos, além de ser caracterizado como conjunto de habilidades técnicas neutras e independentes do contexto social em que são usadas, o que nos remete ao paradigma formal. O segundo vê o letramento como um instrumento a serviço da ideologia, uma vez que cada língua transmite sua visão de mundo, que não é neutra nem objetiva. Ademais, o toma como situado e contextual, o que o insere no paradigma da heterogeneidade.

Embora haja diversas nomenclaturas para os diferentes enfoques dados ao estudo do letramento, todos partilham da ideia de que fatores sociais e individuais interferem nas atitudes dos sujeitos e rejeitam o conceito liberal humanista de letramento como um processo biológico e individual.

Por compreender a língua enquanto uma prática social, o Letramento Crítico vê o sujeito como um agente, um sujeito ativo, versátil, reflexivo e crítico, visto que compreende, por meio da materialização de práticas de letramento em textos, que a realidade é uma representação, que verdades são situadas e que é seu papel questioná-las (LUKE; FREEBODY, 1997; CERVETTI; PARDALES; DAMICO, 2001). Assume, portanto, diversos papéis e tem a possibilidade de ação sobre a sociedade por meio de práticas letradas situadas.

\section{Considerações finais}

Neste artigo propomo-nos a expor brevemente algumas correntes teóricas pertencentes aos paradigmas formalista e funcionalista, focando no elemento sujeito e em como ele se constitui em cada uma delas. Assim, percebemos que, no estruturalismo saussuriano, o sujeito é visto como inconsciente e passivo, pois a língua, apesar de social, preexiste e é anterior a ele, enquanto que, no gerativismo, ele é tomado como um indivíduo biológico pertencente a uma comunidade ideal com capacidade inata para linguagem. Extrapolando o paradigma da homogeneidade, que já não conseguia responder às questões impostas pelo desenvolvimento da ciência Linguística, necessário se fez abrir o campo para a heterogeneidade constitutiva da língua.

\footnotetext{
2 A Linguística Aplicada é um campo de estudo inter/trans/indisciplinar que investiga problemas ligados à linguagem da vida real, concebendo-se de forma continuamente problematizadora. (MOITA LOPES, 2013).
} 
Dessa forma, a Sociolinguística retoma o conceito de sujeito, agora com vistas a um falante que "atua de acordo com as disposições estruturadas em que a prática linguística se realiza" (LUCCHESI, 2004, p. 172), pertencente a uma comunidade de fala real, portanto, heterogênea.

Na Linguística Textual, o sujeito é visto como emissor, falante, produtor de textos, porque possui competência para tal. Na análise de discurso, por sua vez, o sujeito é visto inicialmente como assujeitado (chegando-se a falar até de 'sujeito nulo'), e posteriormente como uma posição. $\mathrm{O}$ sujeito da $\mathrm{AD}$ apresenta-se como descentrado e heterogêneo, atravessado por diversas vozes que o constituem, além de ter a ilusão de ser origem do seu dizer, controlando o sentido do que fala, porém desconhecendo que o que fala está invadido por diversas FDs.

No Letramento Crítico, por sua vez, o sujeito é visto como um ser social, crítico, situado, cidadão participativo, capaz de questionar as representações existentes na sociedade e agir sobre ela.

Por fim, tendo em vista a impossibilidade de completude (por isso são chamadas de escolhas teóricas), foi possível compreender que os paradigmas estão em constante mudança, pois outras questões emergem e devem ser pensadas/consideradas. Consequentemente, as correntes teóricas sofrerão modificações ou serão ultrapassadas para que novas teorias abarquem noções outras advindas do contexto no qual se vive.

\section{Referências}

ARAÚJO, D. L.; RAFAEL, E. L.; AMORIM, K. V. Estudos de oralidade: o ponto de vista na percepção do objeto e suas implicações para a formação docente. In: ARAÚJO, D. L.; SILVA, W. M. Oralidade em foco: conceitos, descrição e experiências de ensino. Campina Grande: Bagagem, 2013.

BARBOSA, J. R. A. Linguística: outra introdução. Mossoró: Queima Bucha, 2013.

BASÍLIO, R. O lugar do sujeito no sistema saussuriano de língua. Anais do SILEL. Volume 1. Uberlândia: EDUFU, 2009.

BENTES, A. C. Linguística textual. In: MUSSALIN, F.; BENTES, A. C. (Org.) Introdução à linguística: domínios e fronteiras. São Paulo: Corte, 2001, p. 245-287.

BRANDÃO, M. H. N. Introdução à análise do discurso. Campinas: Editora da Unicamp, 1990.

BRANDÃO, M. H. N. Introdução à análise do discurso. Campinas: Editora da Unicamp, 1997.

CERVETTI, G.; PARDALES, M. J.; DAMICO, J. S. A tale of differences: comparing the traditions, perspectives and educational goals of critical reading and critical literacy. Reading Online, $\quad$ v. 4, n. 9, Apr. 2001. Disponível em $<\mathrm{http}: / / \mathrm{www}$. readingonline.org/articles/art_index.asp?HREF=cervetti/index.html > Acesso em 30 mar. 2013. 
CHOMSKY, N. Aspectos da teoria da sintaxe. Trad. de J. A. Meireles e E. P. Raposo. Coimbra: Armênio Amado, 1975.

CHOMSKY, N. Syntatic structures. The Hague: Mouton, 1957.

CHOMSKY, N. O conhecimento da língua, sua natureza, origem e uso. (Trad.) EUA: Caminho, [1986]1994.

FAIRCLOUGH, N. Discurso de mudança social. Brasília: Editora Universidade de Brasília. 2001.

FERNANDES, C. A. Análise do Discurso: reflexões introdutórias. Goiânia: Trilhas Urbanas, 2005.

FERNANDES, C. A. Análise do discurso: reflexões introdutórias. $2^{\mathrm{a}}$ ed. São Carlos: Claraluz, 2007.

HALLIDAY, M. A. K. An introduction to functional grammar. $3^{\text {rd }}$ ed. London: Hodder Arnold, 2004.

HEINE, L. M. B. Reflexões sobre o sujeito social e o sujeito ideológico. 2008. p. 327 - 343.

KOCH, I. G. V. Desvendando os segredos do texto. São Paulo: Contexto, 2004.

LABOV, W. Sociolinguistics Patterns. Oxford: Basil Blackwell, 1972.

LUCCHESI, D. Sistema, Mudança e linguagem: um percurso na história da lingüística moderna. São Paulo: Parábola Editorial, 2004.

LUKE, A.; FREEBODY, P. Critical literacy and the question of normativity. In: MUSPRATT,S.; LUKE, A.; FREEBODY, P. (Eds.) Constructing critical literacies. St. Leonards: Hampton, Press, 1997.

MARQUES, W. Funcionalismo, pragmática e análise do discurso: reflexões analítico-críticas. Revista Odisseia. $\mathrm{n}^{\circ} \quad 3$ 2009. ISSN: 18832435. Disponível em: < ufrn.emnuvens.com.br/odisseia/article/download/2055/1489>. Acesso em 15 dez 2013.

MOITA LOPES, L. P. (Org.) Linguística aplicada na modernidade recente: festschrift para Antonieta Celani. São Paulo: Parábola, 2013.

MOREIRA, H; CALEFFE, L. G. Metodologia da pesquisa para o professor pesquisador. $2^{\mathrm{a}}$ ed. Rio de Janeiro: Lamparina, 2008.

NÓBREGA, M. Sujeito e sistema em Saussure: Uma relação possível? ReVEL. Edição especial n. 2, 2008. [www.revel.inf.br]

ORLANDI, E. Análise de Discurso: Princípios e Procedimentos. São Paulo: Pontes, 2002. 
POSSENTI, S. Teorias do discurso: um caso de múltiplas rupturas. In: BENTES, A. C.; MUSSALIN, F. Introdução à Linguística: fundamentos epistemológicos. Vol. 3. São Paulo: Cortez, 2004. p. 353-392.

SAUSSURE, F. [1916] Curso de Lingüística Geral. 28ª Ed. São Paulo: Cultrix, 2007.

SAUSSURE, F. Escritos de linguística geral. Trad. Bras. Carlos Augusto Salum e Ana Lúcia Franco. São Paulo: Cultrix, 2004.

SEVERO, C. G. A comunidade de fala na sociolinguística laboviana: algumas reflexões. Revista Voz das Letras. Concórdia, Santa Catarina, Universidade do Contestado, n. 9. sem. 1, 2008.

SILVA, F. M. As dicotomias saussurianas e suas implicações sobre os estudos linguísticos. REVELLI - Revista de Educação, Linguagem e Literatura da UEG - Inhumas. v. 3, n. 2 - p. $38-55$, out. 2011.

SILVA, F. P. Arquivo e memória na descrição/interpretação de enunciados In: SILVA, A. M. M. et all (Org.) De memória e de identidade: estudos interdisciplinares. Campina Grande: EDUEPB, 2010. p. 67-82.

STREET, B. V. Literacy in theory and practice. Cambridge: Cambridge University Press, 1984.

WILSON, C. D. R. J. Relações interpessoais em um fórum de discussão online: A Perspectiva sistêmico-funcional em práticas discursivas de ensino a distância. Rio de Janeiro, 2008. 268 f. Tese (Doutorado em Letras). Pontifícia Universidade Católica.

ZANUTTO, F.; NAVARRO, P. Discurso da mídia e identidade jovem: a história e a memória em letras e imagens In: SILVA, A. M. M. et al. (Orgs). De memória e de identidade: estudos interdisciplinares. Campina Grande: EDUEPB, 2010. p. 35-66.

Recebido em: julho de 2014.

Aprovado em: setembro de 2014. 